\title{
La cosmogonía chibcha en la obra de Luis Alberto Acuña
}




\section{$7 \mathrm{POLI}$ \\ POLITÉCNICO
GRANCOLOMBIANO \\ INSTITUCIÓN UNIVERSITARIA}

\section{La cosmogonía chibcha en la obra de Luis Alberto Acuña}

(C) Diego Carrizosa Posada

(c) INSTITUCIÓN UNIVERSITARIA POLITÉCNICO GRANCOLOMBIANO

Primera edición: diciembre de 2018

ISBN: 978-958-8721-83-5

e-ISBN: 978-958-8721-85-9

ePub-ISBN: 978-958-8721-84-2

Publicaciones Politécnico Grancolombiano

Eduardo Norman Acevedo

Líder de Publicaciones

Calle 57 \# 3-00 Este

PBX: 7455555 ext. 1171

E-mail: editorial@poligran.edu.co

Bogotá - Colombia

Analista de Producción Editorial: Paulo Mora Noguera Diseño y Armada Electrónica: Huevofrito SAS

Corrección de Estilo: Eduardo Franco

Impresión: Xpress Estudio Gráfico y Digital S.A.S.

Impreso en Colombia - Printed in Colombia
Carrizosa Posada, Diego Francisco

La cosmogonía chibcha en la obra de Luis Alberto Acuña / Diego Francisco Carrizosa Posada; - Bogotá D.C.: Editorial Politécnico Grancolombiano., 2018.

288 p. : il. color; $17 \times 24 \mathrm{~cm}$.

Incluye referencias bibliográficas.

ISBN 978-958-8721-83-5

e-ISBN 978-958-8721-85-9

ePub-ISBN 978-958-8721-84-2

1.Pintores colombianos - siglo xx 2. Acuña, Luis Alberto, 1904 - 1993 --Crítica e interpretación 3. Cosmología Indígena - Colombia 5. Mitología indígena - Colombia I. Institución Universitaria Politécnico Grancolombiano Il. Tít.

SCDD 927.861

Co-BolUP

Sistema Nacional de Bibliotecas - SISNAB Institución Universitaria Politécnico Grancolombiano.

La editorial de la Institución Universitaria Politécnico Grancolombiano pertenece a la Asociación de Editoriales Universitarias de Colombia ASEUC. "Las opiniones plasmadas en esta obra son de responsabilidad exclusiva de los autor, y no comprometen a las instituciones ni determinan su posición o filosofía institucional".

Ninguna parte de esta publicación puede ser reproducida, almacenada o trasmitida de manera alguna, ni por ningún medio, ya sea electrónico, químico, mecánico, óptico, de grabación o fotocopia, sin permiso escrito de la Institución Universitaria Politécnico Grancolombiano. 


\title{
La cosmogonia chibcha en la obra de Luis Alberto Acuña
}

\author{
Diego Carrizosa Posada
}

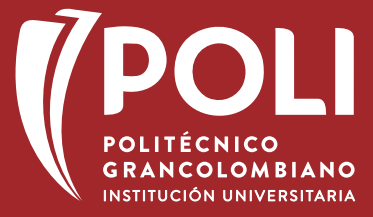



Me di a pintar figuras aisladas y aun dípticos y polípticos de tema rural, mitológico o religioso, en el que el indio, el mestizo, o el mulato, sin perder sus características de tales, eran elevados a la categoría de deidades indígenas o de venerados íconos cristianos.

Luis Alberto Acuña 


\section{Tabla de contenido}

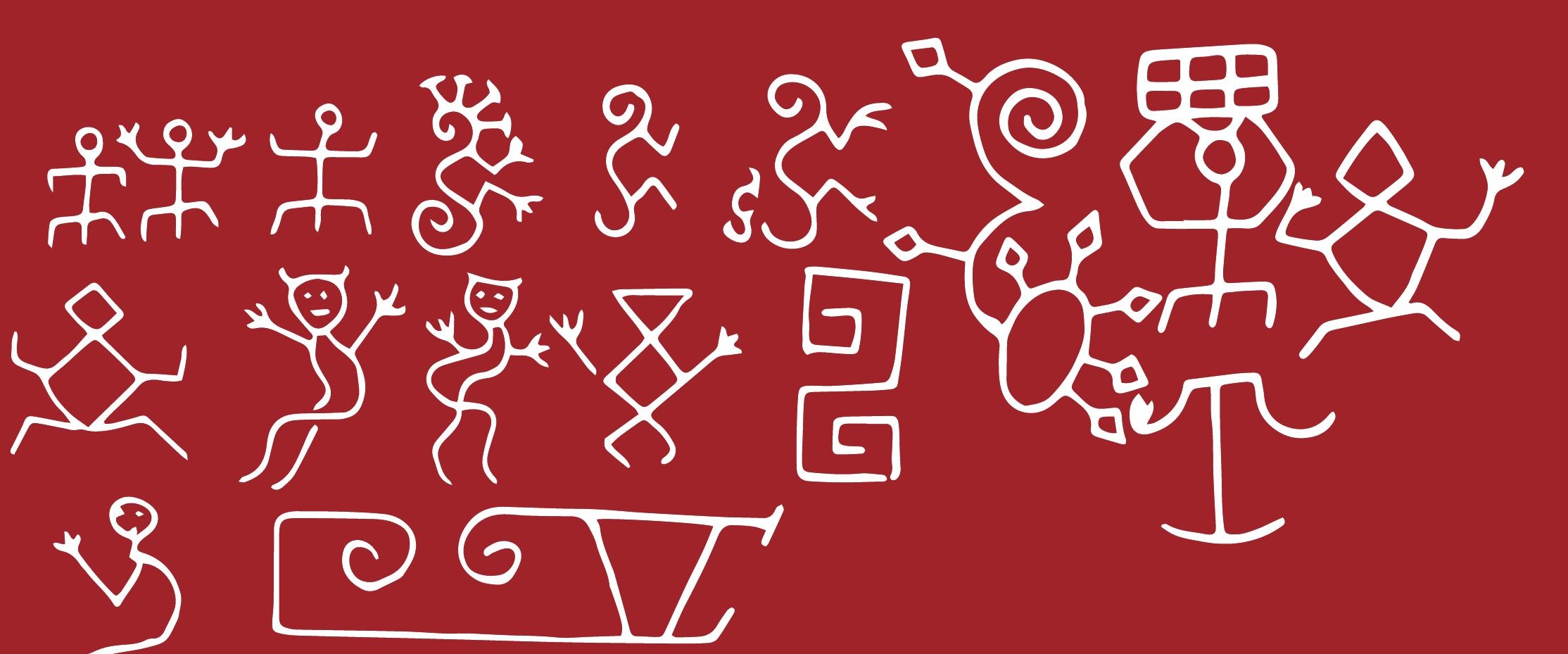


Introducción 19

Agradecimientos $\quad 25$

1. Bosquejo intelectual y artístico de Luis Alberto Acuña: trabajos históricos en la Academia Colombiana de Historia

2. El desarrollo de los movimientos nacionalistas en América Latina: contexto político, social y artístico

3. La revolución visual planteada por los artistas europeos: reflexiones de Luis Alberto Acuña

4. Los estudios del Luis Alberto Acuña: la búsqueda por una expresión nacional

5. El universo chibcha según varios pensadores y la visión de Luis Alberto Acuña como historiador y artista

6. El impacto de los estudios de Luis Alberto Acuña en la estética de su plástica, y la influencia de los pintores muralistas mexicanos

7. Descripción pre iconográfica, análisis iconográfico e interpretación iconológica de la pintura: Bachué, madre generatriz de la raza chibcha (c.1937)

8. Descripción pre iconográfica, análisis iconográfico e interpretación iconológica de la pintura: Retablo de los dioses tutelares de los chibchas (1938)

9. Descripción pre iconográfica, análisis iconográfico e interpretación iconológica del mural: Teogonía de los dioses chibchas (1974) 

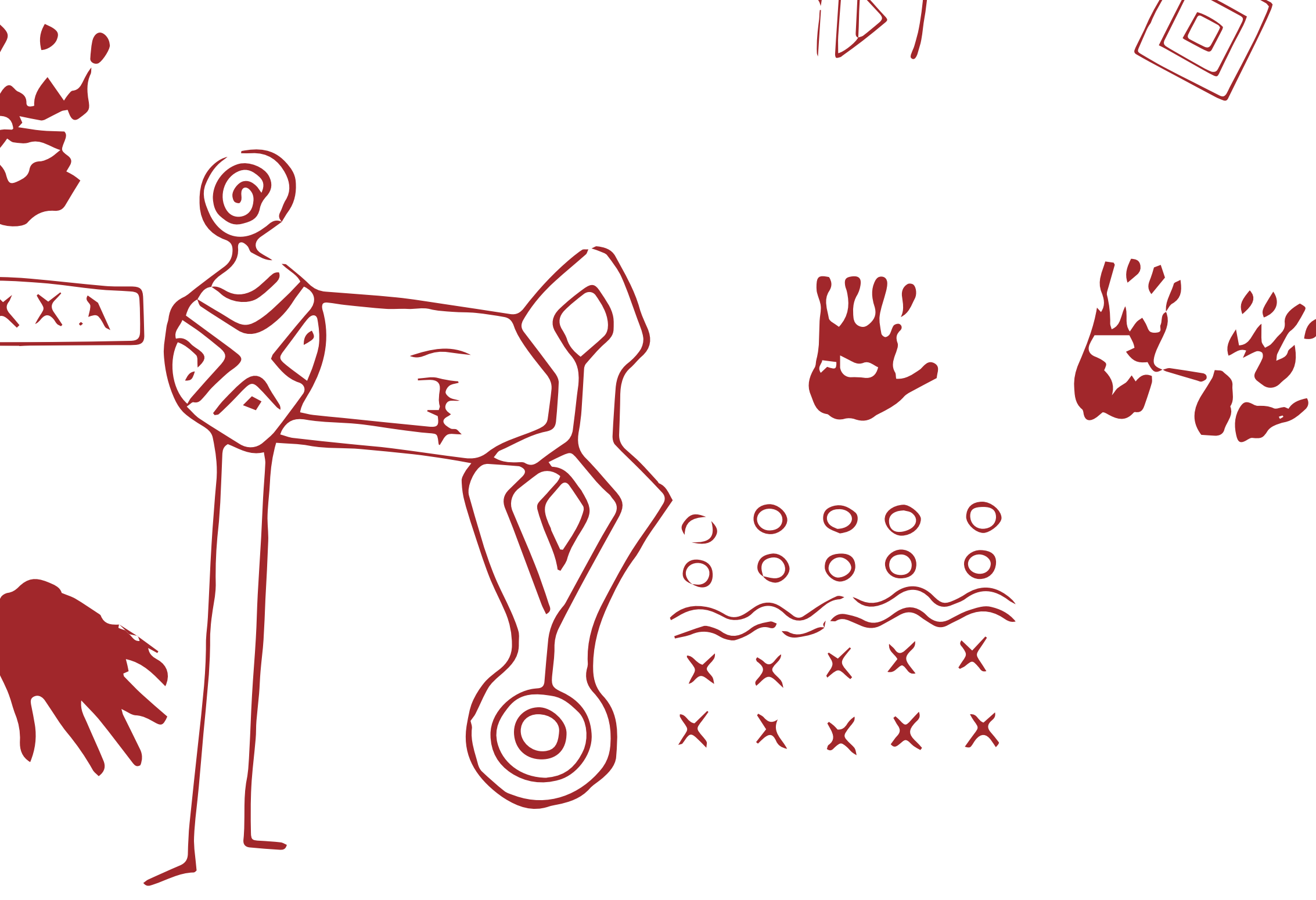

estudiar el arte de los Chibcha en sus diversas manifestaciones, desde los petroglifos hasta la alfarería pasando por el textil y la cerámica, alimentó, con sus escritos, los temas que el pintor Acuña desarrolló en lienzos y muros de grandes dimensiones. El artista se había empeñado, nos recuerda Carrizosa, en exaltar asuntos de importancia nacional que habían sido relegados por las generaciones anteriores, por no decir menospreciados.

Al tiempo de cumplir el cometido de conocer al Acuña esencial, el lector de estas páginas podrá constatar que la bibliografía consultada es exhaustiva y en algunos casos, sin caer en presunciones, raya la erudición, ya que la cita y/o el dato utilizados son siempre pertinentes. Como método, el desempeño del autor 
es correcto. Todo planteamiento, juicio, opinión o concepto esclarecedor, previamente expresado sobre Acuña por otros autores, es citado, valorado y explicado, lo que le permite ahondar, enriquecer y potenciar el detalle considerado. Carrizosa se diferencia, así, del historiador pirata que se apropia de aportes contenidos en trabajos anteriores y oculta la respectiva fuente, con la perversa pretensión de pasar por original sin llegar a serlo verdaderamente.

Acuña pertenece al grupo de poetas, novelistas, ensayistas, dramaturgos, pintores, escultores, grabadores y compositores latinoamericanos que, entre 1910 y 1940, se empeñó en dar cuenta de lo que somos humana y socialmente, de cara a nosotros mismos, dándole la espalda a Europa, si bien Europa fue el vientre que engendró y estimuló, a través de las vanguardias, el anhelo de querer alcanzar horizontes propios, un aspecto del que dan cuenta las oportunas citas a los manifiestos suscritos, en los años veinte, por mexicanos y brasileños. Al identificar y asumir dicha aspiración como el eje central de su trabajo, Carrizosa detalla los recursos desplegados por Acuña para alcanzar su propósito, estimulado por el Rómulo Rozo que esculpió, en 1926, Bachué, diosa generatriz de los indios chibchas.

Rescatar el legado cultural de los Chibcha y mostrar el ambiente húmedo y semi selvático que este pueblo indígena respiró en los alrededores de la capital de Colombia, se volvió, para Acuña, un imperativo y un reto. De allí sus libros y artículos sobre el tema. Es interesante, entonces, que Carrizosa ha leído y releído al maestro para proceder, a continuación, a revisar las fuentes que debió considerar; entre ellas, además de los vestigios dispersos en sitios arqueológicos y colecciones de arte, las suministradas por los cronistas españoles que Acuña consultó para realizar las dos partes de un mismo y honrado trabajo intelectual: la parte del historiador primero; luego, la del pintor y escultor. De paso, Carrizosa nos recuerda que el antropólogo e historiador Juan Friede, mentor de Acuña y autor de una magnífica y ejemplar monografía sobre su obra artística, también escribió sobre los Chibcha. La mención y la figura de Friede ilustran el ambiente cultural de esos años y ayuda a comprender las inquietudes que abrigaron los jóvenes de la época.

Hay, entonces, un contexto detallado que le permite concluir a Carrrizosa, apoyándose en la teoría de Edwin Panofsky, que el maestro pintó en sus cuadros a Bachué, Bochica, Chaquén, Chibchacún, Chía, Cuchaviva, Chiminichagua, Huitaca, Iguaque, Nemcatatoa, Sía y Sua, los dioses del panteón chibcha. En lo que hace a los funcionarios de este pueblo precolombino, Acuña representó el cacique, el jeque, el zaque y el zipa. Yendo un poco 
más allá, el autor explica que la presencia de serpientes, ranas y otros animales obedece a que hacían parte de su iconografía tradicional. Por último, el autor se fija en los paisajes de Acuña e identifica la flora nativa para hacernos ver cuán exigente fue al concebir y realizar sus temas.

Carrizosa ha centrado su trabajo en el análisis de apenas 37 obras. Alega, en una clara muestra de honradez intelectual, que no pudo localizar y estudiar algunas obras conocidas a través de fotos, por lo que las descartó de plano. No obstante, los capítulos discurren sin presentar lagunas, ya que este libro abunda y es concreto por el solo hecho de considerar, in extenso, tres pinturas que son clave para el cabal conocimiento y la justa apreciación de Acuña. Esas pinturas son Bachué, madre generatriz de los indios chibchas (ca. 1937), Retablo de los dioses tutelares de los chibchas (1938) y Teogonía de los dioses chibchas (1974). Se trata de obras ambiciosas que resumen, en efecto, lo que el imaginario poético del historiador y pintor pudo concebir y materializar desde la palabra escrita, antes de pasar a volcarlo en imágenes visuales. En conclusión, este estudio de Diego Carrizosa es minucioso y preciso, es decir, completo y lúcido.

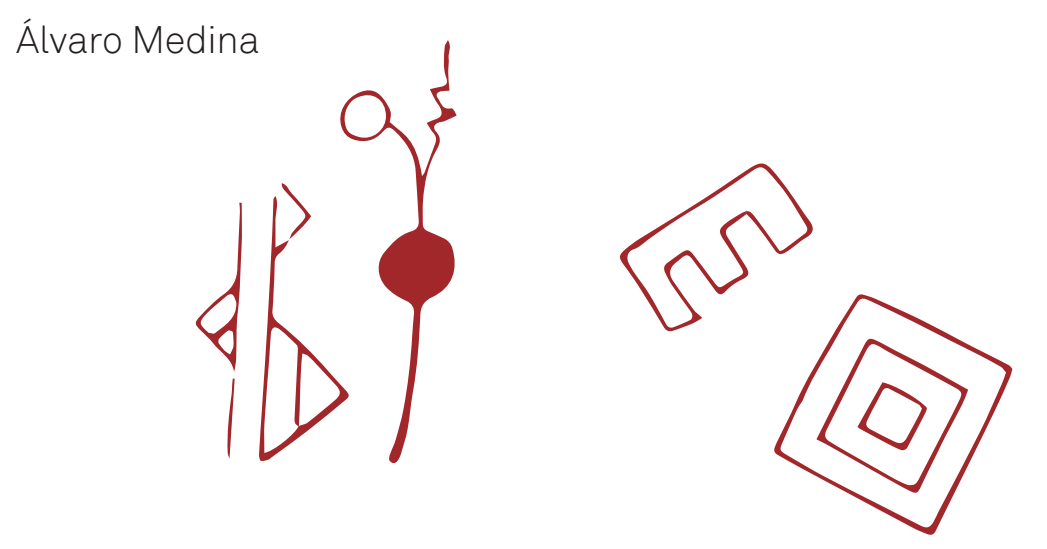




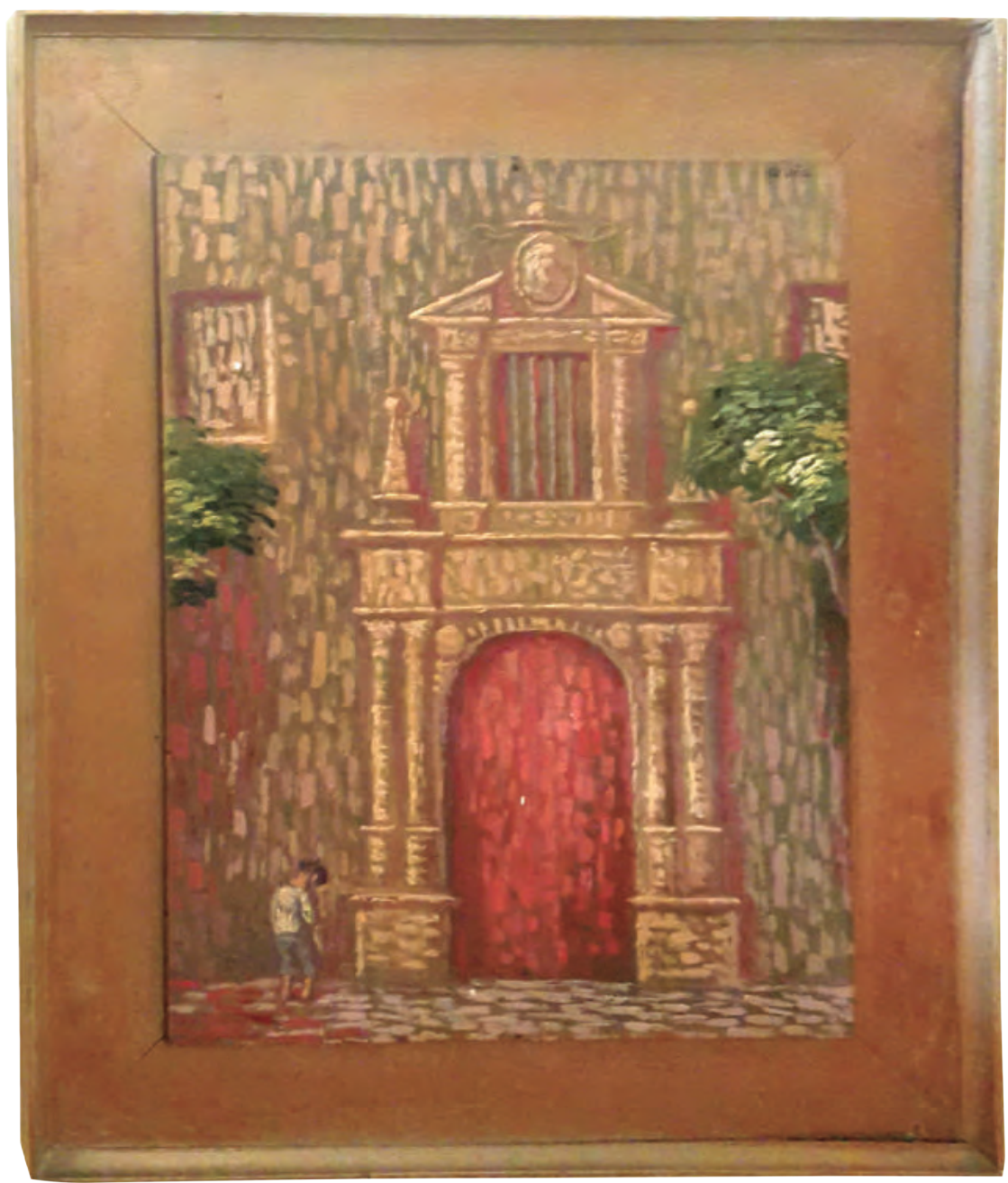

Sin título. Óleo sobre lienzo. Luis Alberto Acuña (s.f.) Fuente: Colección privada. Fotografía: Diego Carrizosa. 


\section{Metodología}

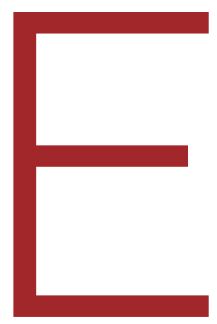

I presente libro indaga sobre la obra del pintor y escultor Luis Alberto Acuña y estudia de qué modo este artista expresa la cosmogonía chibcha dentro su obra literaria y plástica. Así es como Luis Alberto Acuña, mediante los resultados de una producción literaria - que se nutre de las narraciones de los cronistas y de otros autores- influidos por la escuela mexicana, idealiza plásticamente la cosmogonía de la cultura chibcha a partir de la construcción de un lenguaje de temáticas autóctonas.

Con el objetivo de informar al lector sobre la metodología de trabajo que se implementó en este libro, se puede señalar que se aplicó la investigación histórica mediante una estrategia descriptiva, bajo un tipo de análisis hermenéutico. Fue elegida la investigación histórica, porque se refiere a la comprensión de los hechos del pasado y se aplica a las ciencias sociales, puesto que permite estudiar y examinar elementos que son el resultado del desarrollo de hechos específicos, desde los orígenes de su aparición, las razones para su evolución y su relación con el estado actual del acontecimiento. Por su parte, para 
el análisis de las obras se aplicó el método de la escuela de Erwin Panofsky (1995), que consiste en una descripción pre-iconográfica, un análisis iconográfico y una interpretación iconológica, instancias que vistas en su conjunto comprenden el proceso de historiar la tradición.

A continuación, de acuerdo con Ramírez (2010), se presentan los elementos principales que comprenden cada instancia:

“Descripción pre-iconográfica (significación primaria o natural). La identificación de objetos y acciones produce un sentimiento llamado significado expresivo, que funciona por empatía. En otras palabras, lo que se busca en este nivel es identificar los motivos y describir lo que perciben los sentidos: a. Identifica las formas puras (representaciones de objetos, humanos, plantas, etc.). b. Capta las relaciones mutuas (acontecimientos o cualidades expresivas). c. A partir de esta percepción formal, se busca el significado fáctico, el cual se logra con la identificación de ciertas formas visibles con ciertos objetos conocidos, según la experiencia práctica. d. Analiza la obra dentro del campo estilístico y la ubica en el periodo artístico que el tratamiento de sus formas indiquen. e. Determina el asunto ma- terial tanto en lo formal como en lo expresivo. Análisis iconográfico (significación secundaria o convencional).

Es el reconocimiento de la figura; explica y clasifica una imagen determinada dentro de una cultura específica: a. Determina el tema. b. Analiza los elementos que acompañan la obra, sus diferentes atributos o características. c. Construye el mundo de las imágenes, historias y alegorías. $d$. Se nutre de fuentes literarias.

Interpretación iconológica (significación intrínseca o de contenido). Consiste en descubrir los valores simbólicos de una obra de arte: a. Buscar su significación. b. Analiza la obra en su contexto cultural intentando comprender su significado en el tiempo en el cual se ejecutó (Ramírez 2010, 122-123)".

En cuanto a los aspectos descriptivos, se hace hincapié en la opción de recrear disertaciones de tipo conceptual. De igual manera, se tienen en cuenta las nociones de tiempo y de cronología de los hechos (Cerda, 1998).

En torno al análisis hermenéutico, su aplicación responde a la utilización de principios de información escrita que preservan la creación de conocimiento histórico. Esta modalidad de análisis 
permite comprender el sentido de los textos y su contexto histórico-cultural. La aplicación del concepto hermenéutico facilita involucrase de forma directa con el universo y contexto sociocultural del autor objeto de estudio, y permite al investigador la "comprensión" del texto desde otras miradas y hacer énfasis en la intersubjetividad (Ramírez, 2010).
Autorretrato. Óleo sobre Lienzo.

Luis Alberto Acuña. (1964).

Fuente: Colección privada.

Fotografía: Diego Carrizosa.

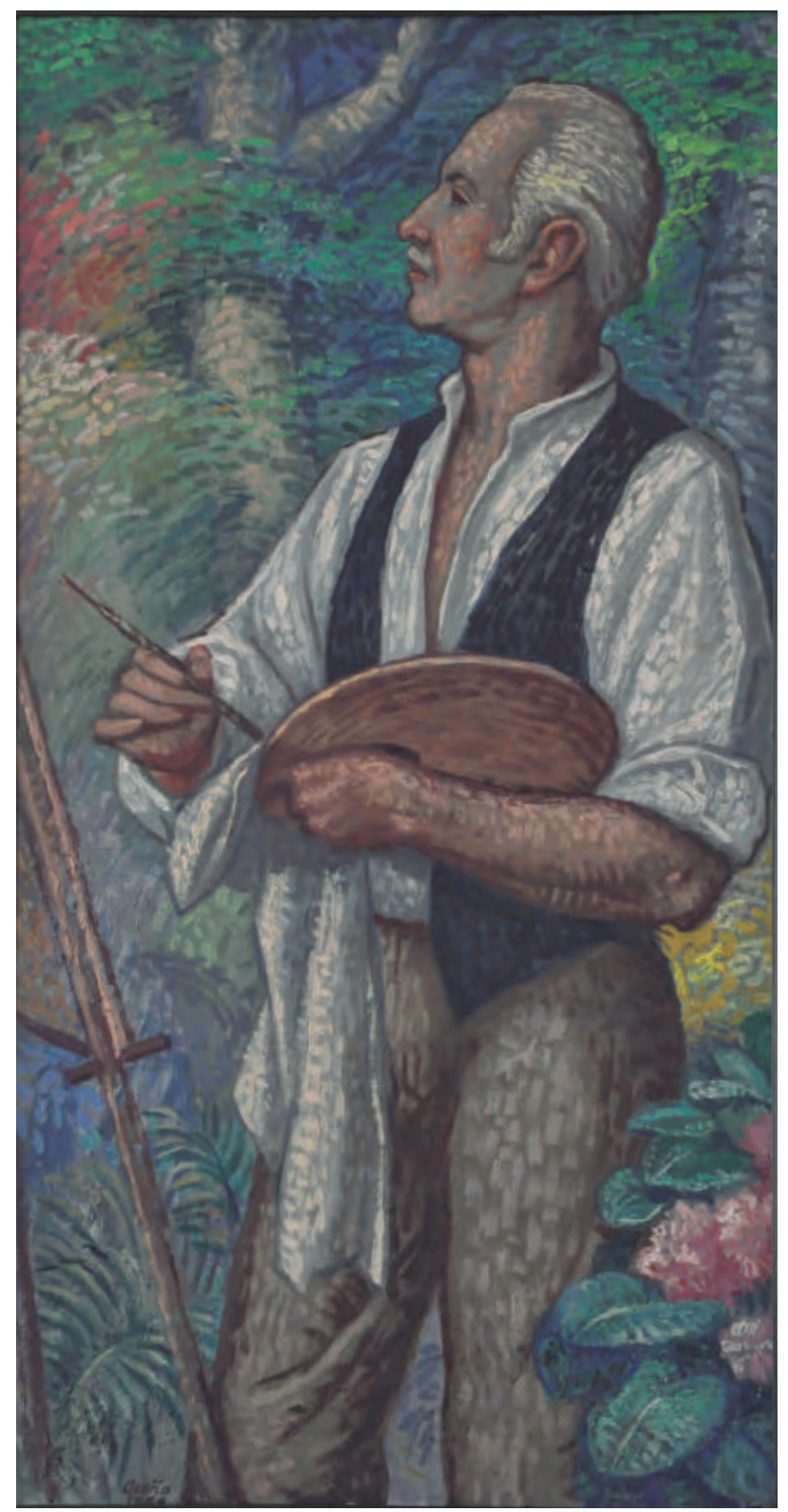

La cosmogonía chibcha | Luis Alberto Acuña | 17 

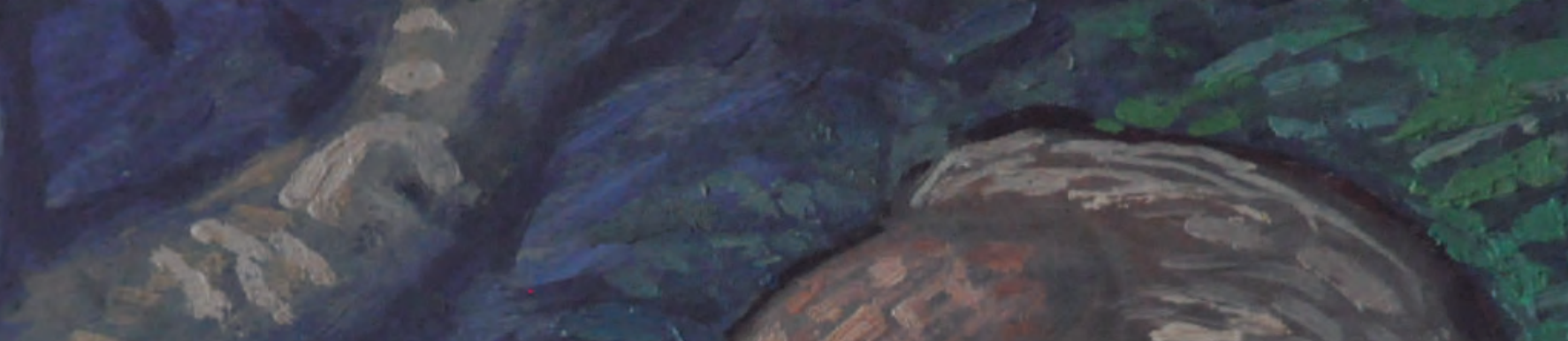

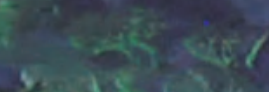

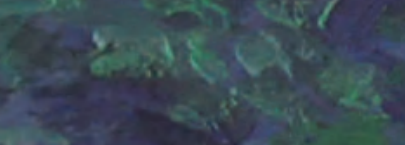

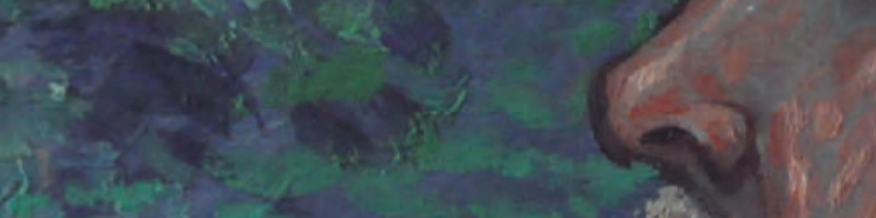

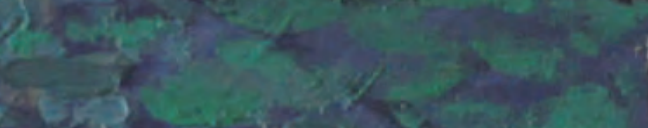

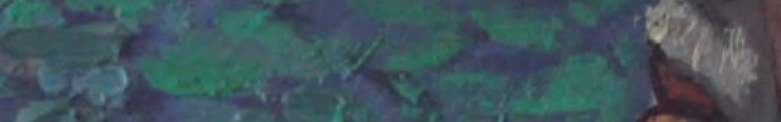
makes $x^{2}-2 x+4$

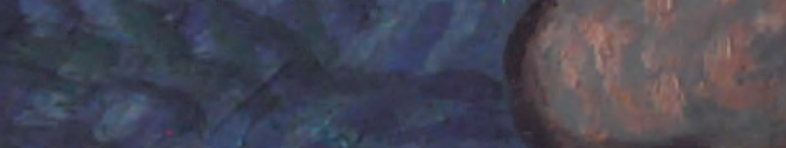

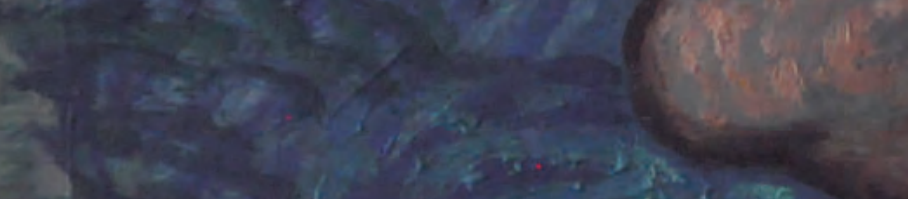

4.

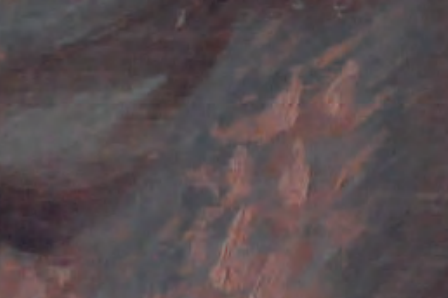

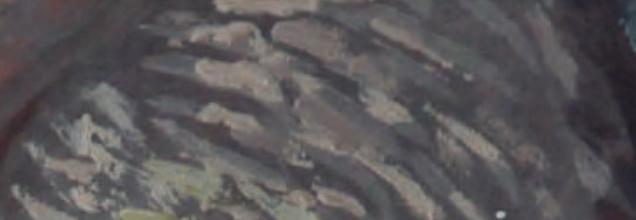

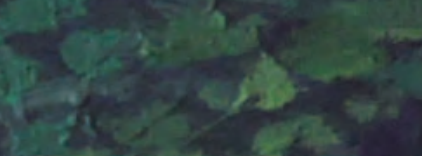
(3) I. $\frac{5}{5}$

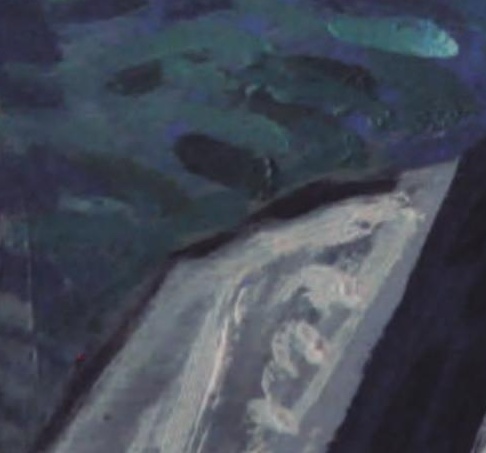

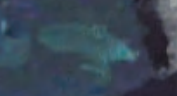




\section{Introducción}

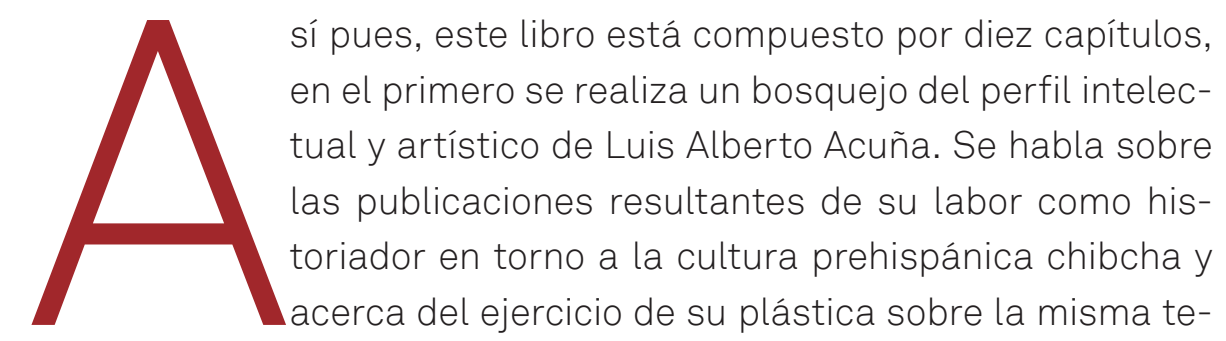

mática. Se hace referencia a sus estudios y experiencias obtenidas en Francia, Italia, Alemania, España y México. Se conoce acerca de sus aportes como docente universitario y rector de la Escuela de Bellas Artes de Bogotá, sobre su participación en las diferentes versiones del Salón Anual de Artistas Colombianos, y se provee información en torno a los premios obtenidos y las instituciones nacionales e internacionales que poseen su obra en colección.

El segundo capítulo se refiere a los hechos políticos, sociales y artísticos que tuvieron lugar en Colombia y América Latina desde inicios de los años veinte hasta los años cuarenta del siglo pasado, y que permitieron que se desarrollaran diferentes movimientos de 
carácter nacionalista. Se exponen las teorías del político e intelectual mexicano José Vasconcelos, del político marxista peruano de origen indígena José Carlos Mariátegui, y se explica la manera en que la corriente ideológica indigenista nacionalista fue conocida y adaptada al contexto colombiano por parte de políticos, intelectuales y artistas plásticos, hechos que resultaron en el inicio de la investigación antropológica en el país. En el caso específico de los pintores y escultores, se estudió la manera en que su ejercicio artístico reflejó una ruptura con la influencia academicista, mediante la obtención de un lenguaje plástico con una clara connotación social y patriótica.

El tercer capítulo versa sobre la revolución visual planteada a comienzos de los años veinte, por parte de los artistas europeos de la primera vanguardia, quienes se nutrieron del arte tribal americano, oceánico y africano para forjar un lenguaje plástico con características modernas. Se indagó sobre el pensamiento de Luis Alberto Acuña en torno a las soluciones plásticas que permitieron que se establecieran vínculos entre las obras de los artistas europeos y las del arte tribal, y la manera en que los artistas colombianos de la generación del treinta percibieron este tipo de arte. Se reflexionó de igual manera sobre el concepto de lo "glocal", teoría concebida por el sociólogo norteamericano Roland Robertson que se refiere a los "localismos globales", cuyas nociones se pueden reflejar en la obra de algunos artistas europeos de comienzos del siglo XX, como Henry Matisse y Maurice de Vlaminck.

El cuarto capítulo tiene que ver con la manera en que surgió en Colombia el discurso nacionalista que se nutrió del ideario planteado en la Monografía del bachué, texto del cual se derivaron las nociones teóricas y plásticas que algunos pintores y escultores reflejaron en sus creaciones artísticas, y que comprendieron las tendencias que se refieren a los temas prehispánicos y a la valoración al campesino.

Son explicados los postulados que atañen a El manifiesto de movimiento de los artistas independientes, y la manera en que emergen en la obra de Pedro Nel Gómez y de sus seguidores. Se habla sobre las razones por las que el pensamiento de la intelectualidad colombiana a finales de la década del treinta no le otorgaba el valor científico, y artístico al arte indígena, como tampoco a los descubrimientos arqueológicos.

En el quinto capítulo se ilustra al lector sobre los orígenes y la estructura de la cultura chibcha 
antes de la conquista, de acuerdo con el pensamiento de otros autores, así como de Acuña. Se trata el tema que concierne a las nociones sobre el concepto de expropiación del universo simbólico de una sociedad prehispánica.

Se explica la metodología de estudio implementada por Luis Alberto Acuña sobre el arte rupestre, como es el caso de la figura del "animal encorvado" y las representaciones cosmogónicas chibchas del zipa y del zaque, cuyos resultados emergieron tanto en sus publicaciones como en su plástica.

El sexto capítulo se refiere al impacto de los estudios de Acuña en la estética de su plástica y a la influencia que recibió su obra por parte de los pintores muralistas mexicanos. Se explica la manera en que Acuña reflexionó sobre la creación de un tipo de arte que respondiera a una expresión americana, el cual requería para su puesta en escena una forma, un estilo y un concepto, respuesta que Acuña encuentra en las formas redondas y sensuales que emergen en los cuerpos pintados por Diego Rivera. En este capítulo se conoce además sobre las variaciones estéticas y temáticas que sufrió la obra de Acuña, cuando recibió la influencia de las corrientes artísticas internacionales que aparecieron durante los años cincuenta del siglo pasado y la manera en que la crítica especializada comentó sobre tales creaciones.

En el capítulo número siete se desarrolla la metodología de estudio de obras de arte desarrollado por Erwin Panofsky (1995). La primera obra sobre la cual se realiza dicho análisis corresponde a la pintura de Acuña titulada Bachué, madre generatriz de la raza chibcha (c.1937), en ella se efectúa una descripción pre iconográfica (determinación del asunto formal: luz, color y pincelada, y en lo expresivo se describe lo que perciben los sentidos). El análisis iconográfico, consiste en es tudiar los elementos que comprenden el mundo de las imágenes, historias y alegorías que emergen en las representaciones de personajes y objetos que aparecen en la obra. Por último, se efectúa la interpretación iconológica, que radica en examinar la significación intrínseca o de contenido de la obra dentro del contexto cultural, para comprender lo que ella significó en el tiempo en el cual se realizó.

El octavo capítulo comprende de igual manera el desarrollo de la disciplina de estudio de Panofsky (1995), pero esta vez es aplicada al trabajo de Acuña titulado Retablo de los dioses tutelares de los chibchas (1938). Para tal efecto son desarrolladas las instancias de análisis que responden a 
la descripción pre iconográfica, que determina el asunto material tanto en lo formal como en lo expresivo, al análisis iconográfico que comprende la significación secundaria o convencional de la pintura, y a la interpretación iconológica que revisa la pintura dentro del contexto cultural en el cual se trabajó.

En el capítulo noveno se examina bajo la metodología de estudio de obras de arte de Panofsky (1995), el mural Los dioses tutelares de los chibchas (1974). Se aplica igualmente el proceso de descripción pre iconográfico, el cual se encarga de determinar en la obra el asunto material en lo formal y expresivo y describir lo que perciben los sentidos. En el análisis iconográfico se trabaja la significación secundaria o convencional y en la interpretación iconológica se efectúa un proceso de revisión del mural, con el propósito de percibir lo que el mural significó dentro del momento histórico que le correspondió.

El décimo capitulo corresponde a las conclusiones, dentro de las cuales se considera pertinente puntualizar que Luis Alberto Acuña se puede considerar como el único artista plástico colombiano, que dentro del contexto nacional y latinoamericano, interpretó y representó en pintura de ca- ballete y mural, en una sola composición, así como en un conjunto, una visión idealizada de casi todas las deidades que hacían parte del universo cosmogónico chibcha, inclusive las que en su propio momento histórico los propios chibchas no representaron, sino por interpuesta persona por respeto a su devoción.

Se puede concluir también que las teorías publicadas por Acuña en 1935, pudieron haber contribuido dentro del inicio del proceso de adquisición y consolidación de información por parte de investigadores pertenecientes a disciplinas nacientes en Colombia, como la arqueología y la etnología, para coadyuvar a reconocer como obras de arte a los trabajos artísticos prehispánicos, e incidido a otorgar el valor que merecen las mismas como objetos de investigación, contribuyendo de manera importante a que el país tomara conciencia de la existencia y la importancia de las culturas prehispánicas en la construcción de la Nación. 


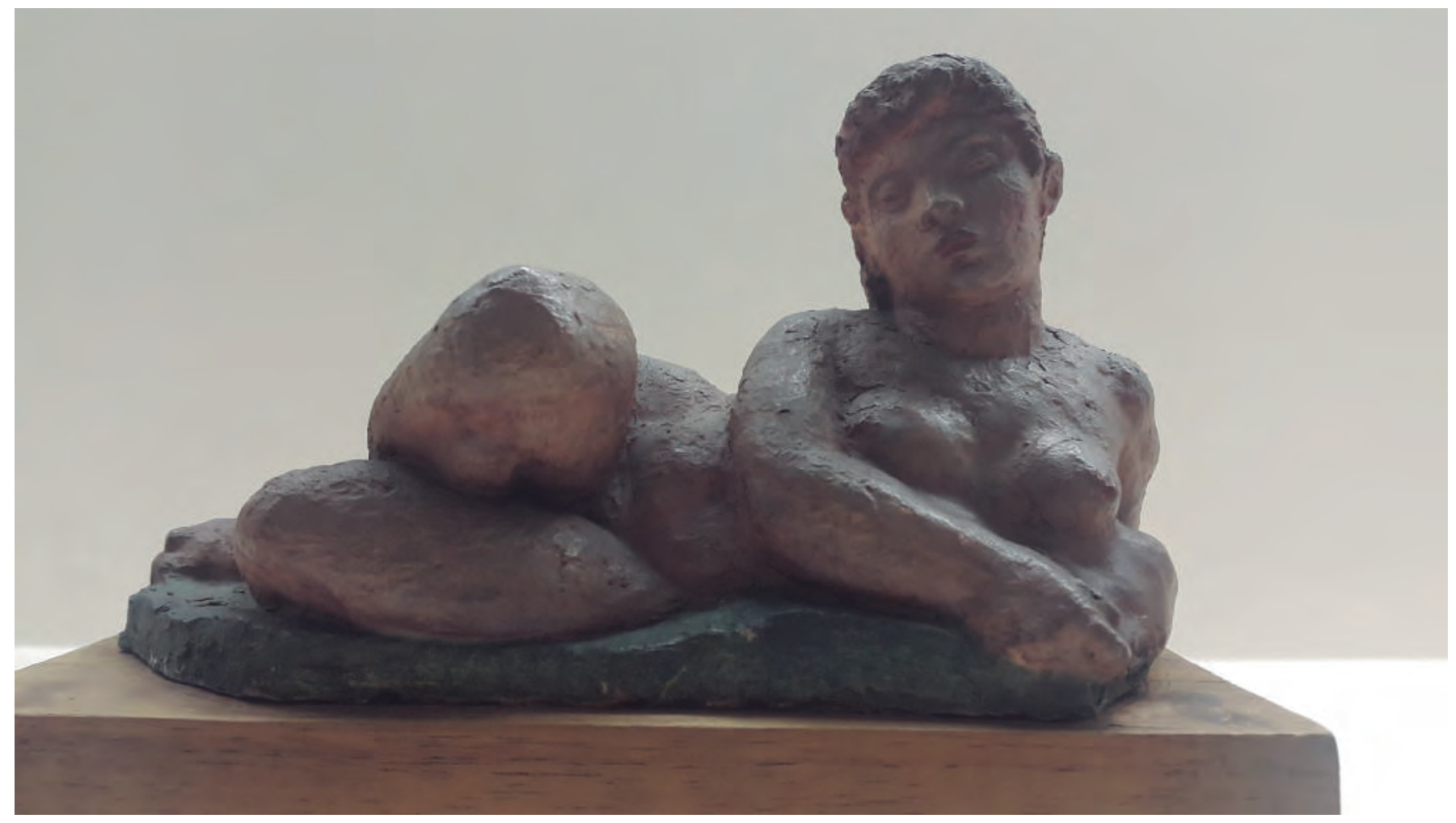

Reposo. Terracota. Luis Alberto Acuña. (1950). Colección: Museo Nacional de Colombia. Reg. 2320. Fotografía: Diego Carrizosa. 


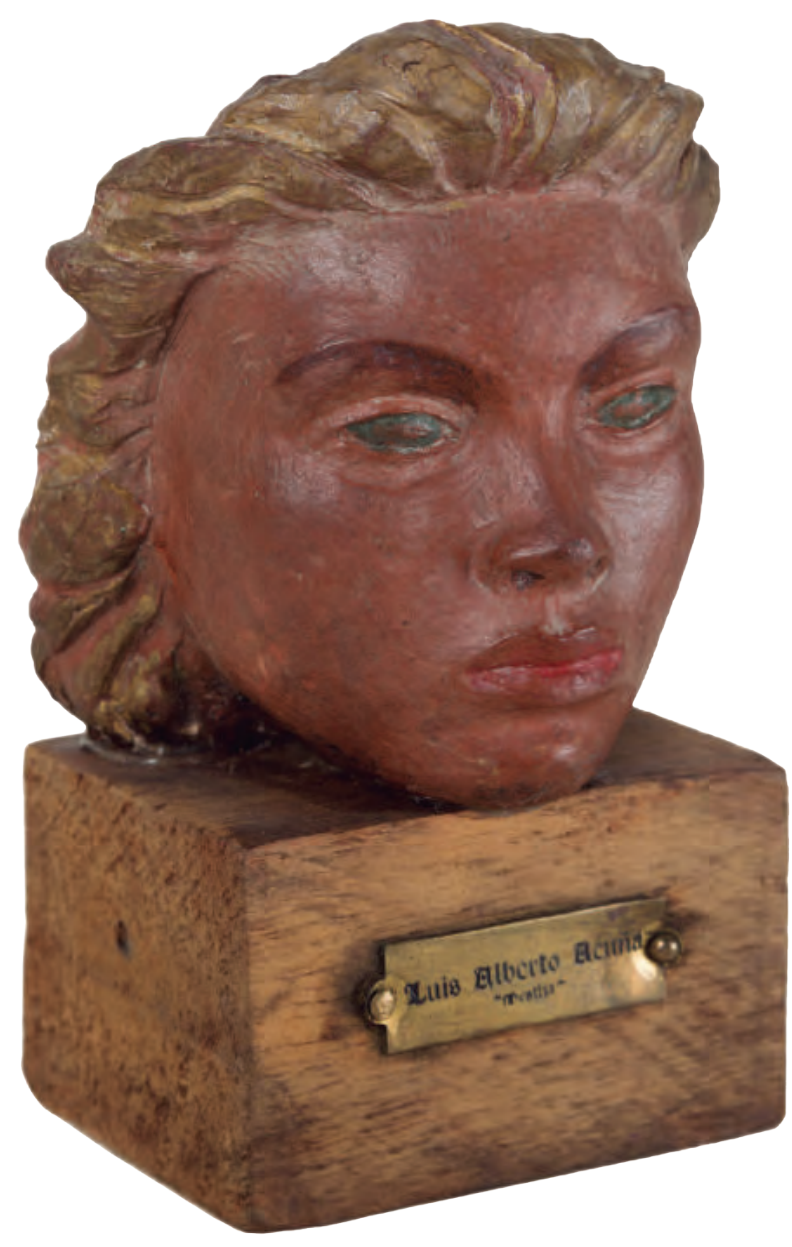

Luis Alberto Acuña Tapias (1904-1993) / Ladrillera de Pantaleón Gaitán Mestiza. (Ca.1949). Moldeado (Arcilla). 12.1 x 7.3 × 6 cm. Colección: Museo Nacional de Colombia, reg. 2321. Fotografía: @ Museo Nacional de Colombia / Samuel Monsalve Parra. 


\section{Agradecimientos}

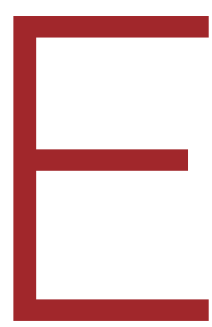

n primera instancia le agradezco mi esposa María Luisa Hernández y a mi hijo Tomás Carrizosa Hernández, a quienes les quité tiempo valioso de vida familiar mientras escribía este libro y, sin embargo, persistentemente con gran entusiasmo me fortalecieron los ánimos cuando decaía. A mi papá Julio Carrizosa Umaña de quien cito en este libro algunos párrafos obtenidos del resultado de sus investigaciones sobre el tema del medio ambiente, y a quien constantemente le agradezco sus valiosas recomendaciones. Gracias a mi mamá, María Cristina Posada por haberme introducido a los textos y al conocimiento del destacado historiador experto en artes plásticas, profesor Álvaro Medina con quien siempre estaré en profundo agradecimiento. Así como por el motivarme a conocer el pensamiento del filósofo y académico Francisco Posada Díaz, quien fuese experto en temas como el marxismo, el subdesarrollo, la violencia y la sociedad chibcha. Gracias también para mi estimado profesor Alberto Vargas, quien me otorgó su competente asesoría académica durante la escritura de este libro. 
Gratitudes para todos los descendientes del maestro Luis Alberto Acuña Tapias, sin cuya amable colaboración en la cesión de derechos de reproducción de las obras de su ancestro, este libro nunca hubiese sido posible ser publicado. Ellos son Alonso Acuña Cañas (q.e.p.d.) quien me colaboró en su momento en la obtención de información y localización de las obras del maestro Luis Alberto Acuña. Se le agradece de especial manera a su hijo Martín Alonso Acuña González quien me brindó su apoyo en la ubicación de todos los descendientes del maestro Acuña, así como a sus hermanos Charito Acuña González, Luis Alberto José Gabriel Acuña González y María Carolina de los Ángeles Acuña González. Agradecimientos a Julio Acuña Cañas. Como se le agradece también a Aurora Acuña Cañas, así como a sus hijos Juan Manuel Acuña Acuña, María Cristina Acuña Acuña, Martha Lucía Acuña Acuña, José Gabriel Acuña Acuña y Aurora Acuña Acuña.

A Ferrando Acuña Cañas (q.e.p.d.) y a sus hijos Andrés Ferrando Acuña Martínez y María del Pilar Acuña Martínez, muchas gracias. Reconocimientos de igual forma para Gabriela Acuña Torres, así como para su hermana Marta Lucía Acuña Torres.

Muy agradecido con Yolanda Guerra viuda de Luis Alberto Acuña Tapias y con sus hijas Juana y María Victoria Acuña Guerra, quienes desde mis primeras investigaciones sobre las obras del maestro Acuña, me abrieron siempre con gran amabilidad y cariño las puertas de la Casa Museo Luis Alberto Acuña de Villa de Leyva, departamento de Boyacá para poder fotografiar las obras del maestro Acuña allí expuestas.

Se les agradece también a las entidades custodias de las obras del maestro Acuña, como son el Museo Nacional de Colombia, la Biblioteca Luis Ángel Arango, quienes me autorizaron a fotografiar las pinturas, así como obtener los permisos de reproducción de las mismas. Gracias para el Mayor General Orlando Salazar Gerente General de la Sociedad Hotelera Tequendama S.A, quién durante su administración autorizó, la publicación de las fotos del mural Teogonía de los dioses chibchas (1974), por parte del autor de este libro, quien en algunos momentos de su niñez observó al maestro Acuña mientras trabajaba en el mural. Se le agradece de igual manera a la señora Adriana Vergara Ejecutiva de Banquetes del hotel, quien me permitió estudiar y fotografiar el mural en numerosas oportunidades.

Muchas gracias para la señora Victoria Barragán administradora del Centro Médico Almirante Colón, quien me permitió fotografiar el mural Colón descubre el nuevo mundo (1959), que hace parte de la recepción de dicha entidad. 
Exalto la participación del Museo del Oro, entidad que me licenció publicar algunas fotos obtenidas por este autor sobre unas piezas de arte prehispánico pertenecientes a la cultura muisca, y especiales agradecimientos para el señor Clark M. Rodríguez por su amabilidad al cederme sus fotos sobre la misma temática. De igual manera al Museo Arqueológico MUSA y al señor Roberto García Poveda por autorizar la publicación de las fotografías tomadas por él sobre unas piezas de alfarería muisca. De manera especial un reconocimiento a los investigadores Diego Martínez Celis y Álvaro Botiva Contreras, quienes muy amablemente me autorizaron reproducir cuatro imágenes de su autoría publicadas en su página web "Introducción al Arte Rupestre". También a la señora Claudia Triana Soto, quien consintió la reproducción de algunas imágenes publicadas en los libros escritos por su bisabuelo Miguel Triana, como son La civilización chibcha y El jeroglífico Muisca. Gracias también a la señora Laura López, quien me permitió la publicación de una foto de su autoría sobre la figura lagartiforme, que conforma los petroglifos de Usamena, del Departamento de Boyacá.

En la Institución Universitaria Politécnico Grancolombiano, se le agradece de manera especial a los funcionarios que hacen parte del Departamento de Desarrollo Investigación e Innovación
I+D+I, puesto que me apoyaron constantemente en la idea de publicar este libro, como son: Sandra Rojas Directora Posgrados, Investigación y Bibliotecas, Eduardo Norman Coordinador de Producción Editorial y David Ricciulli Coordinador Fomento a la Investigación. De igual manera se le dan las gracias al Dr. Sergio Hernández, antiguo decano de la Facultad de Mercadeo, Comunicación y Artes, al Dr. Carlos Augusto García, decano de la facultad de Sociedad, Cultura y Creatividad, así como al director de la Escuela de Artes Visuales y Digitales, profesor Harvey Murcia por haberme coadyuvado en la realización de esta publicación.

A los dos correctores de estilo Susana Lleras y Eduardo Franco, quienes me colaboraron en diferentes oportunidades para que este libro tuviera un texto pulcro, y por último a Ana María Sánchez Baptiste, quien realizó el diseño y diagramación. Muchas gracias. 

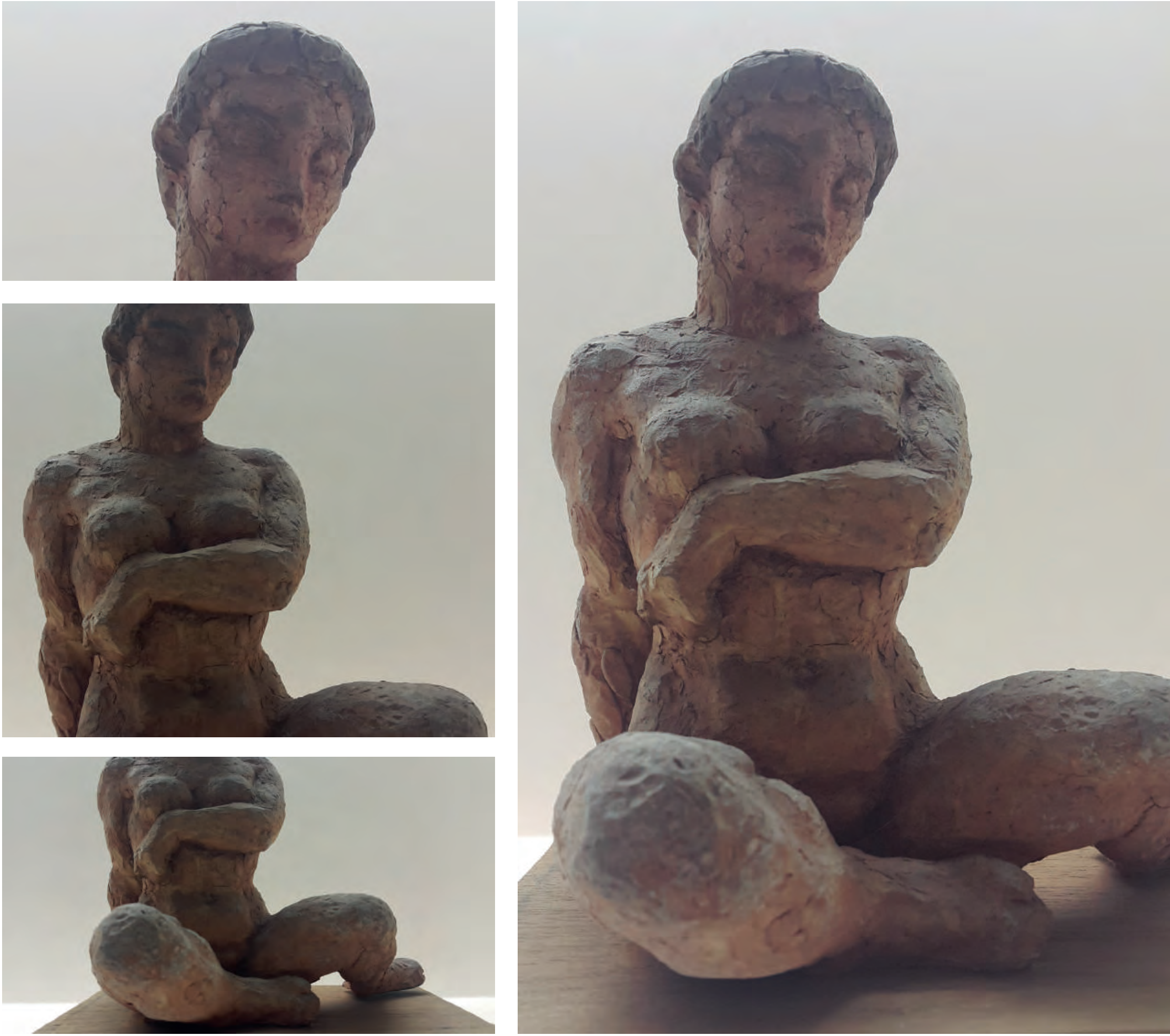